Western University Scholarship@Western

1979

\title{
Depreciation and Maintenance of Houses
}

Stephen Margolis

Follow this and additional works at: https://ir.lib.uwo.ca/economicsresrpt

Part of the Economics Commons

Citation of this paper:

Margolis, Stephen. "Depreciation and Maintenance of Houses." Department of Economics Research Reports, 7917. London, ON:

Department of Economics, University of Western Ontario (1979). 
ISSN :

0318-725X

ISBN :

$0-7714-0094-2$

RESEARCH REPORT 7917

DEPRECIATION AND MAINTENANCE

OF HOUSES

by

Stephen Margolis

June 1979 
While it is clear that a building will deteriorate quite rapidly if no maintenance is provided, there appears to be some question in the housing 1iterature as to whether a building will provide the same quantity of service over time under normal circumstances, if "normal" or reasonable maintenance is provided. The question posed therefore is: Does the quantity of service provided by given structures diminish over time? More specifically: Are there quasi-fixed factors embodied in a structure which will be allowed to diminish by a profit maximizing landlord in an environment where prices are unchanging? Section one provides a review of the literature. This review is aimed at demonstrating two related contentions: that much of the urban 1iterature relies on ad hoc assumptions regarding aging of structures and that there is little agreement among researchers on this subject. Section two presents a model of landlord behavior in which depreciation occurs but maintenance is possible. A result of this model is that conventional assumptions on the cost of maintenance imply a steady state solution in which a positive quantity of capital is embodied in the structure. Such a result would conflict with the notion of filtering of housing, which suggests that houses are allowed to decline in quality with the passing of time. However, it will be suggested that we cannot have the usual confidence in restrictions imposed on technology, so some additional cases are investigated. It is shown that filtering is a posstbility if there are increasing returns to scale in the maintenance activity. The result that neither outcome is uniquely suggested a priori motivates the empirical investigation which is reported in Section three.

It should be noted that this is an economic question, and not simply a technological one. We can be sure that a building left unmaintained will lose value. Alternatively, a structure could be maintained in original condition 
indefinitely with sufficient expenditure, since, at worst, the owner could rebulld the structure in every period to original specifications. Neither extreme need be profit maximizing, so it is necessary to find out what efficient behavior is like. A second point is that casual empiricism is not terribly helpful, and is likely to be misleading. It is certainly possible to point to specific examples of structues which have deteriorated. But likewise it is possible to point to structues which are hundreds of years old which are still quite desirable. Further, the difficulty in disentangling the effects of vintage from the effect of age per se, is likely to confound observation. Similarly, changes in transport technology have been a large and persistent disturbance to the environment in which housing is produced. This has made some past investments inappropriate, a hazard to which newer construction has not yet been subjected. However, the fact that recent experience may involve disturbances which leads to disinvestment should not cause us to conclude that quality decline occurs even in the absence of exogenous disturbance.

\section{Review of the Literature}

Hall [6] provides a discussion of the various ways in which time may affect the valuation of the flow of services from capital goods. That decomposition provides a very useful clarification of the concepts and terminology to be used here. As with housing, there is a problem with capital goods in general of separating price and quantity from a single observed measure of structure or machine value. Hall writes $x_{t \tau}=p_{t}{ }_{t \tau}$ where $x_{t \tau}$ is the value of capital services derived from a single capital good of age $T$ at time $t, z_{t \tau}$ is the number of units of capital service derived from a capital good of age $\tau$ at time $t$ and $p_{t}$ is the price of a unit of capital services at time $t$. In turn, capital 
service is defined by $z_{t \tau}=\Phi_{\tau} b_{t-\tau} d_{t}$ where $\Phi_{\tau}$ indexes wear and tear, $b_{t-\tau}$ is the index of the capital embodied at time $t-\tau$ (embodied technology) and $d_{t}$ indexes disembodied technology, i.e., the effect of present practices on the usefulness of the capital good. The decomposition is a natural one, since the effect of time on a process can presumably be confined to the date of Inception, the date today and the difference between the two. Hall demonstrates that some normalization is necessary, and for housing it is reasonable to Impose the simplifying restriction that $d_{t}=1$ for all $t$. This leaves $\Phi(T)$ and $b(t-\tau)$ as determinants of capital services. Notice that $t-\tau$ is the vintage of a particular unit of capital, so $b(t-\tau)$ is constant for a given dwelling. $\Phi(\tau)$ reflects all of the hazards of age, i.e., both wear and tear and obsolescence. Both the empirical and theoretical treatment of age here will ignore the distinction between wear and tear and obsolescence. The two are probably inseparable empirically. Further it is of little economic importance whether, for example, the heater is inefficient because it is broken or because fue 1 is relatively expensive. The remaining effect, $b(t-T)$ is of considerable empirical importance. This term, indexing the so-called vintage effect, reflects the "goodness" of the capital good as it was originally constituted.

The literature of filtering models represents the most significant attempt to analyze the effects of age on dwellings. While the term filtering has been variously employed, it apparently is understood to mean a change in either the quality of service provided by a structure of the relative socioeconomic position of its occupants. For the most part, filtering models have such changes occurring in equilibrium. To obtain such results, these models generally require some assertion that maintenance does not fully offset the effects of time. The earliest paper is by Ratcliff [15] who states that a house does "move downward in quality and value scales as it ages". Lowry 
argues that "with normal maintenance the quality of a dwelling unit could be preserved indefinitely" [11, p. 363]. However, a fall in rents, which is argued to result from the desire of high income people to occupy newer dwellings, causes landlords to curtail maintenance, which diminishes quality, which further reduces rents, etc., so that units deterioriate until they are demolished. Why people prefer new units if quality is unchanged is a question only partially addressed by Lowry's postulating the existence of something called "market quality" which differs from "social quality", the latter being the attribute which is sustainable with normal maintenance. Market quality is effected by obsolescence while social quality is not. William Grigsby [4] suggests that the depreciation which affects houses is an amalgam of several factors, including the anticipated termination of the flow of services, obsolescence, and wear and tear. Units do decline in quality, but prices or any other influences on landlord behavior, are denied any role in determining depreciation rates.

In general these early filtering models assign a minimal role to prices and provide little analysis of maintenance technology. The modern manifestation of the filtering mode1, provided by Sweeney [23 and 24] remedies each of these deficiencies to some extent.

Sweeney's model identifies the housing market as a hierarchy of housing quality categories. All consumers are indifferent among units within a category, and categories are ranked in the same order by all consumers. The major departure from previous models of filtering is specific consideration of the effect of relative prices on supply and demand of housing by quallty category. Consumers maximize their own utilities in choosing among categories. Suppliers maintain so long as the marginal cost of maintaining a structure within a category plus the return to the structure when a lower category is 
less than the rent in the present category. A price increase in any category will increase the amount of time for which maintenance of the unit within the category is profitable. Units flow into a category from higher categories, and flow out to lower categories. With this, the stock in category 1 is equal to the number of units constructed in all categories greater than or equal to 1 , times the number of periods an average unit spends in the $1^{\text {th }}$ category.

A key assumption for Sweeney is that the discounted total cost of maintaining a unit in category $i$ for a period of time equal to $x_{i}$ is strictly convex in $x_{i}$. Thus, the marginal cost of tenure time in any category is an increasing function [24]. This would suggest some reduction of the capital embodied in a structure with the passage of time. If the marginal cost of time in a category were constant, this would imply that the landlord replaced capital and so succeeded in undoing the action of time by his maintenance activities. But the necessary assumption for Sweeney is stronger, and suggests that maintenance hides, but does not offset the effect of aging. Sweeney's assumptions produce the result that in equilibrium, there is filtering from higher to lower quality categories.

In recent years, two major simulation models have been developed. The Urban Institute housing model (deLeeuw and Struyk, 1975) contains very specific assumptions regarding depreciation and maintenance in the production of housing. This model assumes a production function such that the maintenance of a dwelling at constant quality certainly would appear feasible. However, there is a curfous inconsistency in the Urban Institute model. The difference between rent and operating cost is assumed to decline over time at a rate conjectured to be $20 \%$ per decade $[8, p .28]$. This must occur as either a change in prices or a decline in the capital service derived from the structure. Such a 
methodical decline of the price of housing services or increase in input prices seems unlikely, so one must guess that deLeeuw and Struyk have in mind the second alternative. However, their model specifies both a constant rate of gross depreciation and a diminishing marginal productivity of. maintenance efforts (as seen in their production function). These assumptions are shown below to be inconsistent with the conclusion of a continuing decline of capital over time.

The N.B.E.R. Urban Simulation model [9] contains a housing sector which is essentially another filtering model. Some units will filter into the next lowest quality category unless the structure price difference between the two cateogires exceeds $130 \%$ of the difference in construction cost between the same two categories [P. 116]. Since market equilibrium requires that construction cost differences must equal price differences for categories in which construction occurs, the N.B.E.R. model is one in which equilibrium is associated. with some amount of filtering.

Another fairly large branch of the literature concerns the estimation of hedonic prices for housing. The results of the well known study by Kain and Quigley [10] are interesting in that they find a significant effect of age even though the likely manifestations of age are accounted for by an extensive 1ist of regressors. A more recent effort by Straszheim [22] provides an interesting example of the lack of attention given to age of structures in theoretical formulations. In discussing the theoretical foundations of his estimation, Straszheim deals almost exclusively with location and fails even to mention age. However, in all seventy-three of the hedonic price equations for renters, and in seventy of seventy-three equations estimated for owners, age is significant at ninety-five percent. Only the number of rooms is more significant in these equations. In what Straszheim refers to as demand equations, 
the age of structures is significantly related to own prices and occupant's income. The temptation to jump to a conclusion here should be avoided. Neither of these authors were primarily concerned with aging, and therefore there is no disentangling of age and vintage effects.

There exist few attempts to estimate the rate of depreciation directly. Grebler, Blank and Winnick [3] offer estimates of depreciation rates based on F.H.A. appraisals. The F.H.A. data separates land and structure value, and includes an estimate of the current replacement cost of the structure. Grebler, et al., then estimate deterioration by comparing replacement cost with current value. This methodology would seem to be correct, and the implicit definition of deterioration would correspond to the definition chosen in this paper, since obsolescence is included in the value lost. Further, the replacement cost for an equivalent structure allows for current building technologies, so any price decrease due to new development in building technology would be excluded from the observed deterioration. Unfortunately, the details of the F.H.A. procedure may diminish the applicability of these results. While the F.H.A. manual [27] calls for the computation of a discounted net revenue stream, the remaining economic life is to be determined by the appraiser and the manual only suggests data which might be helpful in making such a judgment. In fact, common assessment practice typically involves rules of thumb to predict expected life from the age of structures. Thus, there may be some circularity in the process which Grebler, et al., use to estimate depreciation rates. Assessors start with notions of depreciation, this leads to evaluations of economic life, which in turn lead to determination of present market value, which these authors use to estimate depreciation. Further, the manual suggests that appraisers use higher discount rates for older structures where age increases the uncertainty of income. It would seem reasonable that much of the loss in value reflected in the F.H.A. data would relate to shorter predicted life expectancies and higher discount rates for older properties. 


\section{A Model of the Production of Housing Services}

The model presented here considers the landlord as maximizing the present value of the dwelling by choosing optimal paths for maintenance and other expenditures. The ultimate rate of deterioration (net depreciation) will be endogenous, determined by the amount of reinvestment. However, there is an underlying rate of deterioration (gross depreciation) of the capital embodied in a structure which is exogenous. That means, for example, that while it is assumed that the paint flakes at a predetermined rate, it is also assumed that repainting is possible. The model postulates an infinite horizon, though not necessarily an infinite life. This assumption is reasonable given the existence of resale markets.

Following Muth [14] and others, it is assumed here that the attributes of a dwelling unit can be aggregated to an index of housing quality, or units of housing service, Q. Further, assume a production function for housing services $Q(t)=Q(N(t), K(t), L)$ where

L is the land occupied by the structure;

$\mathrm{K}(\mathrm{t})$ is the quantity of capital embodied in a dwelling at time $t$;

$N(t)$ is the quantity of operating input employed at time $t$, that is, the nondurable input.

We assume that the quantity of land $L$ is fixed for a building once constructed; it does not depreciate, and cannot be adjusted. It is assumed that $K(t)$, $N(t), L \geqq 0$.

It should be noted that without prior restrictions on housing technology, the distinction between $K(t)$ and $N(t)$ is arbitrary. Observers have noted a continuum of inputs according to durability, with perhaps heating fuel being the least durable, and concrete foundations the most durable. In this 
sense, the distinction between $\mathrm{N}$ and $\mathrm{K}$ would depend largely on the time period which is considered.

The third input, land, requires some further discussion. The notion of land employed here is unfortunately, but necessarily, quite limited. The simple notion of land as a particular number of square feet is inadequate; when an individual purchases a residential lot he acquires a fairly complex bundle of atributes which includes all of the characteristics of the neighborhood. While we may be comfortable with the assertion that actual surface is seldom varied, neighborhoods clearly do vary. Just how and why neighborhoods change is an important and interesting issue, but one which wIII not be dealt with here. For the theory, ignoring neighborhood change is not especially troublesome. Where neighborhoods become better (worse), rents will be bid up (down). The total price paid for any particular combination of non-land inputs provided at any particular address will rise (fall). In the present context, this would be treated as a change in the price per unit of housing service, rather than as a direct change of the quantity itself. Of course, landlords would be expected to react to the change in price by adjustIng their use of inputs.

Returning to the model, it is next assumed that landlords confront a price schedule $P(Q ; \alpha)$, a continuous and nondecreasing function. The argument $\alpha$ is used as a catch-all shift parameter, used to reflect those market circumstances which affect the price-quantity relationship. $P(Q ; \alpha)$ is the total rental price for a dwelling which offers $Q$ units of housing service. Without $108 s$ of generality, it may be assumed that $\left.\mathrm{P}_{\mathrm{Q}} \alpha^{(}\right)>0$; that is, increases in $\alpha$ correspond with changes which increase the marginal price of housing. Landlords are assumed to be price takers, meaning that they do not consider 
variations in their own output to affect $P()$ or the prices of inputs. Further, landlords will be assumed to have static price expectations, 1.e., the expected rate of price inflation for all quantities of housing and all housing inputs is the same as that for commodities in general.

Let $w$ be the price of nondurable inputs. Now we may consider the efficient $N(t)$ for any given $K(t)$ and $L$. The landlord will maximize profits for any given $\overline{K(t)}$ :

$$
\max _{N(t)} \Pi=P\{Q(N(t) ; \overline{K(t)}, L) ; \alpha\}-w N
$$

This gives rise to the first order condition:

$$
P^{\prime}\{Q(N(t) ; \overline{K(t)}, L), \alpha\} Q_{N}(N(t) ; \overline{K(t)}, L)=w
$$

This statement has the conventional interpretation that the marginal revenue product is equal to the factor price. For a local maximum, marginal revenue product must be a decreasing function of $N(t)$, near $N *(t)$. Equivalently:

$$
\begin{aligned}
& P^{\prime}\{Q(N(t) ; \overline{K(t)}, L), \alpha) Q_{N N}(N(t) ; \overline{K(t)}, L)+ \\
& P^{\prime \prime}\{Q(N(t) ; \overline{K(t)}, L), \alpha) Q_{N}^{2}(N(t), \overline{K(t)}, L)<0
\end{aligned}
$$

The second order condition is clearly satisfied if the price and production functions are strictly concave in $Q$ and $N(t)$, respectively.

With $N(t)$ determined contemporaneously in this way, we can write the output at $t$ as a function of $K(t)$. Since $L$ is assumed fixed at a particular address, we write $Q *(K(t))$ to be the output as a function of $K(t)$, with $N(t)$ assumed to be optimized and I fixed. For notational convenience, define a new function $F(K(t)) \equiv P\{Q *(K(t))\}-w N . F(K)$ may be thought of as a gross profits function. $F^{\prime}(\mathrm{K})$, the marginal value product function for capital, is assumed to be positive and declining. 
A central issue in this inquiry is the cost of achieving given time paths for capital. The capital purchased at any time $t$ will be : $R_{t}=\left(K_{t}-K_{t-1}+\delta K_{t-1}\right)$, where $\delta$ is the gross depreciation rate for the capital embodied in a structure. For now, $\delta$ is assumed to be constant. The analogue for continuous time is: $R(t)=(\dot{K}(t)+\delta K(t))$. There will be a cost associated with achieving any rate of capital replacement. This cost function is written $m(R)$ with $\mathrm{m}^{\prime}(R)>0$. Several possibilities for the second derivative of this function are discussed below.

The landlord's problem can now be represented as follows:

$$
\begin{aligned}
\max _{R} & \int_{0}^{\infty} e^{-r t}(F(K(t))-m(R(t))) d t \\
\text { s.t. } \dot{K} & =R(t)-\delta K(t) \\
0 & \leqq R(t) \\
R(t) & \leqq A
\end{aligned}
$$

The first of these constraints is the definition of $R$. The second states that the landlord cannot sell off individual units of capital; capital cannot be reduced faster than $\delta \mathrm{K}$. The third places an upper bound on the rate of capital additions. This last requirement is not terribly confining, as this bound may be arbitrarily large.

This problem, as it is now formulated, is typical of a class of problems involving investment decisions where there are costs of adjustment. A discussion of this literature, and solution of the general problem under conventional assumptions may be found in Takayama [25, pp. 685-719].

To obtain the equations which will characterize the solution in all of the cases which follow, we form the Hamiltonian:

$$
H=e^{-r t}(F(K)-m(R))+\lambda(t)(R-\delta K)
$$


$K(t), R(t)$, and $\lambda(t)$ will be written and $k, R$, and $\lambda$ for convenience, with the argument $t$ implied. The method of the maximum principle gives us the following as necessary conditions :

$$
\begin{aligned}
\dot{\lambda} & =\frac{\partial H}{\partial K}=\lambda \delta-e^{-r t} F^{\prime}(K) \\
\dot{K} & =\frac{\partial H}{\partial \lambda}=R-\delta R \\
\frac{\partial H}{\partial R} & =-e^{-r t} m^{\prime}(R)+\lambda
\end{aligned}
$$

With the last of these equal to zero at interior solutions.

Given these equations, it is now possible to consider the nature of the solution under several alternative assumptions regarding maintenance technology. This is taken up below, considering first the most conventional case.

Increasing Marginal Cost of Maintenance

We first consider outcomes where $\mathrm{m}^{\prime \prime}(R)>0$. We have the Hamiltonian and the associated necessary conditions shown in equations (2-5), (2-6), (2-7), and (2-8). The possibility that multipliers will be chosen which lead to boundary solutions gives rise to the first case

$$
\text { (2-9) } \quad \lambda<\mathrm{e}^{-\mathrm{rt}} \mathrm{m}^{\prime}(0)
$$

Therefore $\lambda<e^{-r t} m^{\prime}(R)$ for all $R . R=0$ since $\lambda$, the present value of capital, Is less than the cost. For interior solutions, equation (2-8) becomes :

$$
\lambda-e^{-r t} m^{\prime}(R)=0
$$

Construction of a phase diagram in $R$ and $K$ requires solving from the necessary conditions for a relationship in these variables and their rates of change alone. Differentiating $(2-10)$ with respect to $t$, we have:

$$
\dot{\lambda}=\mathrm{e}^{-r t} \mathrm{~m}^{\prime \prime}(\mathrm{R}) \dot{\mathrm{R}}-r \mathrm{e}^{-r t} \mathrm{~m}^{\prime}(\mathrm{R})
$$


Setting (2-11) equal to (2-6), we have:

$$
e^{-r t} m^{\prime \prime}(R) \dot{R}-r e^{-r t} m^{\prime}(R)=\lambda \delta-e^{-r t} F^{\prime}(K)
$$

Substituting $e^{-r t} m^{\prime}(R)$ for $\lambda$ (from equation (2-10)), and multiplying through by $\mathrm{e}^{\mathrm{rt}}$, we obtain the condition:

$(2-13)$

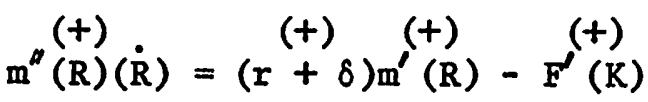

The phase diagram shown in Figure 2-1 is constructed as follows:

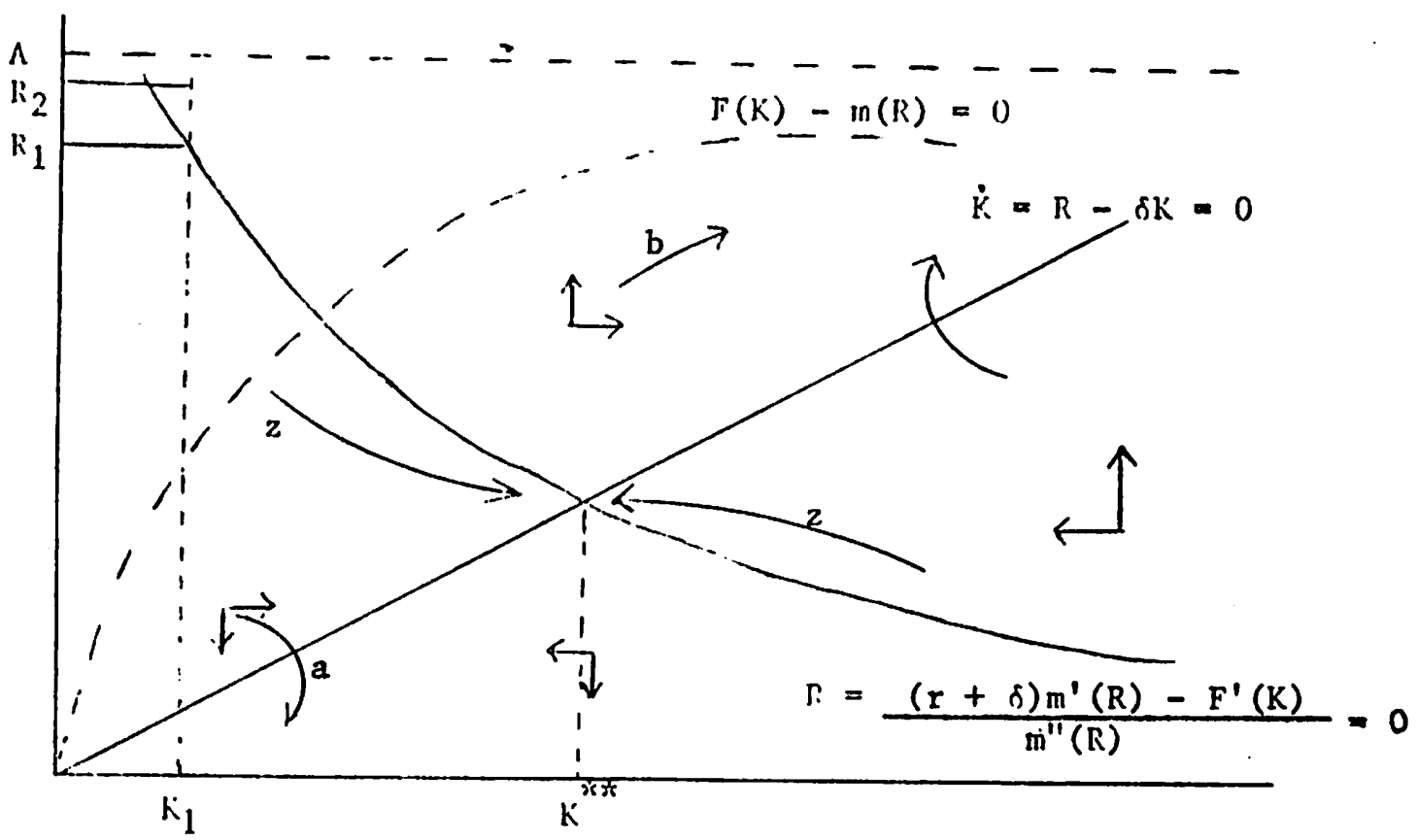

Figure 2-1: Phase diagram for the case of a concave maintenance cost function

From $(2-13), \dot{R}=0$ implies that $F^{\prime}(K)=(r+\delta) m^{\prime}(R) . \quad \dot{K}=0$ implies that $\mathrm{R}=\delta \mathrm{K} . \quad \mathrm{K} * *$ satisfies the condition $(\mathrm{r}+\delta) \mathrm{m}^{\prime}(\delta \mathrm{K} * *)=\mathrm{F}^{\prime}(\mathrm{K} * *)$. The direction of movement with respect to $R$ can also be seen by considering, for a given $K$, the effect of a change in $R$ on the terms in equation (2-13). Fix $K=K_{1}$ and consider an $R$ greater than $R_{1}$ as shown. Moving from $R_{1}$ to $R_{2}$ increases $\mathrm{m}^{\prime}(\mathrm{R})$, making the right-hand side of (2-13) positive. Thus for points above the 
line for which $\dot{R}=0, \dot{R}$ must be positive; that is, $R$ is increasing. It is a standard result that only paths like those labelled $z$ are feastble Euler paths for the infinite horizon case. Paths like those labelled a and $b$ can be shown to violate transversality conditions [13]. Further, since $e^{-r t}(F(K)-m(R))$ and $\dot{K}=R-\delta K$ are concave with respect to $K$ and $R$, the necessary conditions which define the path $z$ are also sufficient. Convergence toward some positive quantity of capital is thus shown to be the optimal response under conditions of increasing marginal maintenance cost. Units may experience filtering down (or up) but filtering would not continue indefinitely.

Up to now, the quantity of capital initially embodied in the dwelling, $\mathrm{K}(0)$, has been ignored. In fact, this is a choice variable at the time of construction. The initial quantity of capital will be chosen so that:

$$
\rho(K(0))=\lambda(0)
$$

where $\rho$ is a marginal price function for capital.

$$
\begin{aligned}
& \lambda(0)=\mathrm{m}^{\prime}(R(0)) \text { from equation }(2-11) \\
& \rho(K(0))=\mathrm{m}^{\prime}(\mathrm{R})
\end{aligned}
$$

If Initial capital purchase occurs at constant unit cost, the problem is fully determined. Initial capital embodiment can be seen at the intersection of the Euler path leading to the steady state solution, and a horizontal line leading from $R$ such that $m^{\prime}(R)=P_{K}$, where $P_{K}$ is the unit price of capital. Intuitively, one might expect that capital is purchases at the time of construction at a price per unit which is lower than the equilibrium replacement cost. In this case, the capital is initially greater than $\mathrm{K} * *$ in Figure 2-1, with infinite convergence on $\mathrm{K} * *$. This would result in 
filtering for a time immediately following construction, but the decline in $\mathrm{K}$ would eventually become negligible.

For the case of convex $m(R)$, it is possible to establish a number of comparative statics results. Note that the arguments $\mathrm{N}$ and $\mathrm{L}$ are sup-

pressed in writing $\mathrm{F}(\mathrm{K})$. Imposing the additional restrictions that $\mathrm{F}_{\mathrm{KK}}, \mathrm{F}_{\mathrm{NN}}<0$ and $\mathrm{F}_{\mathrm{KN}}>0$ it is possible to obtain the following results :

$$
\begin{array}{rlll}
\text { (2-17) } & \frac{\mathrm{dK} * *}{\mathrm{dr}}<0 & \frac{\mathrm{dK} * *}{\mathrm{dw}}<0 & \frac{\mathrm{dK} * *}{\mathrm{~d} \alpha}>0 \\
\frac{\mathrm{dQ} * *}{\mathrm{dr}}<0 & \frac{\mathrm{dQ} * *}{\mathrm{dw}}<0 & \frac{\mathrm{dQ} * *}{\mathrm{~d} \alpha}>0
\end{array}
$$

where $Q * *$ denotes $Q *(K * *)$.

Proofs of these and several additional comparative statics results are provided in [13].

\section{Non-Increasing Costs}

Suspending the restriction that $m(R)$ is convex introduces a number of new possibilities, some of which involve a steady state outcome, some of which do not. This section will demonstrate that filtering outcomes are possible under unusual, but not unreasonable, assumptions on the maintenance cost function. However, the more conventional assumptions of the previous section are not necessary for a steady state solution.

The first and simplest case is that $m^{\prime \prime}(R)=0$. This gives rise to a "knife edge" type of solution. The condition $(\mathrm{r}+\delta)(\mathrm{R} * *)=\mathrm{F}(\mathrm{K} * *)$ defines the optimal capital stock. Whenever that condition is not satisfied capital adjustment occurs at a boundary, with $r=0$ or $R=A$. The optimum requires a steady state at a positive quantity of capital so no filtering occurs in equilibrium under this assumption. 
Another possibility is that the maintenance cost function is concave. This would not be equivalent to economies of scale in the usual sense, because the structure itself or at least the land would enter as a fixed factor. The implicit presence of such fixed factors is of course the usual cause of confidence in the assertion of diminishing marginal products for the variable factors. However in the case of housing there may be some complementarity in activities or the extent of disruption may not vary in proportion to the scale of repair.

When $m(R)$ is concave, filtering is a possibility, as it is possible to show cases in which there is no Euler path compatible with maintenance of a constant quantity of capital.

Again we have the basic equations (2-6) through (2-8). Two boundary cases are considered, since $\mathrm{m}^{\prime}(R)$ might not decline indefinitely. We have:

$$
\lambda<\mathrm{e}^{-r t} \mathrm{~m}^{\prime} \cdot(\mathrm{A}), \mathrm{R}=0
$$

This corner solution would, of course, involve filtering. This filtering outcome is important because interior maxima need not exist with concave $m(R)$. The other boundary solution is:

$$
\lambda>\mathrm{e}^{-r t} \mathrm{~m}^{\prime}(0), \mathrm{R}=\mathrm{A}
$$

Finally, there is the interior solution:

$$
\lambda=e^{-r t} m^{\prime}(R)
$$

Proceeding as to obtain (2-13), we have:

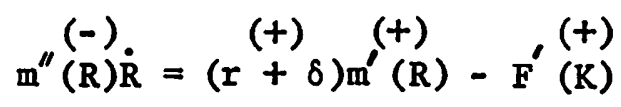

In this case, the objective function is obviously not concave in $R$ since the contrary is explicitly assumed, so paths satisfying equation (2-20) are not necessarily maxima. 
Under the present assumption regarding $\mathrm{m}^{\prime \prime}(R)$, the phase diagram can take on several different appearances. First, the lines satisfying the conditions $\dot{R}=0$ and $\dot{K}=0$ may cross, so that there is some $K * *$ satisfying the equation $(\mathrm{r}+\delta) \mathrm{m}^{\prime}\left(\delta \mathrm{K}^{* *}\right)=\mathrm{F}^{\prime}(\mathrm{K} * *)$. This is shown in Figure 2-2.

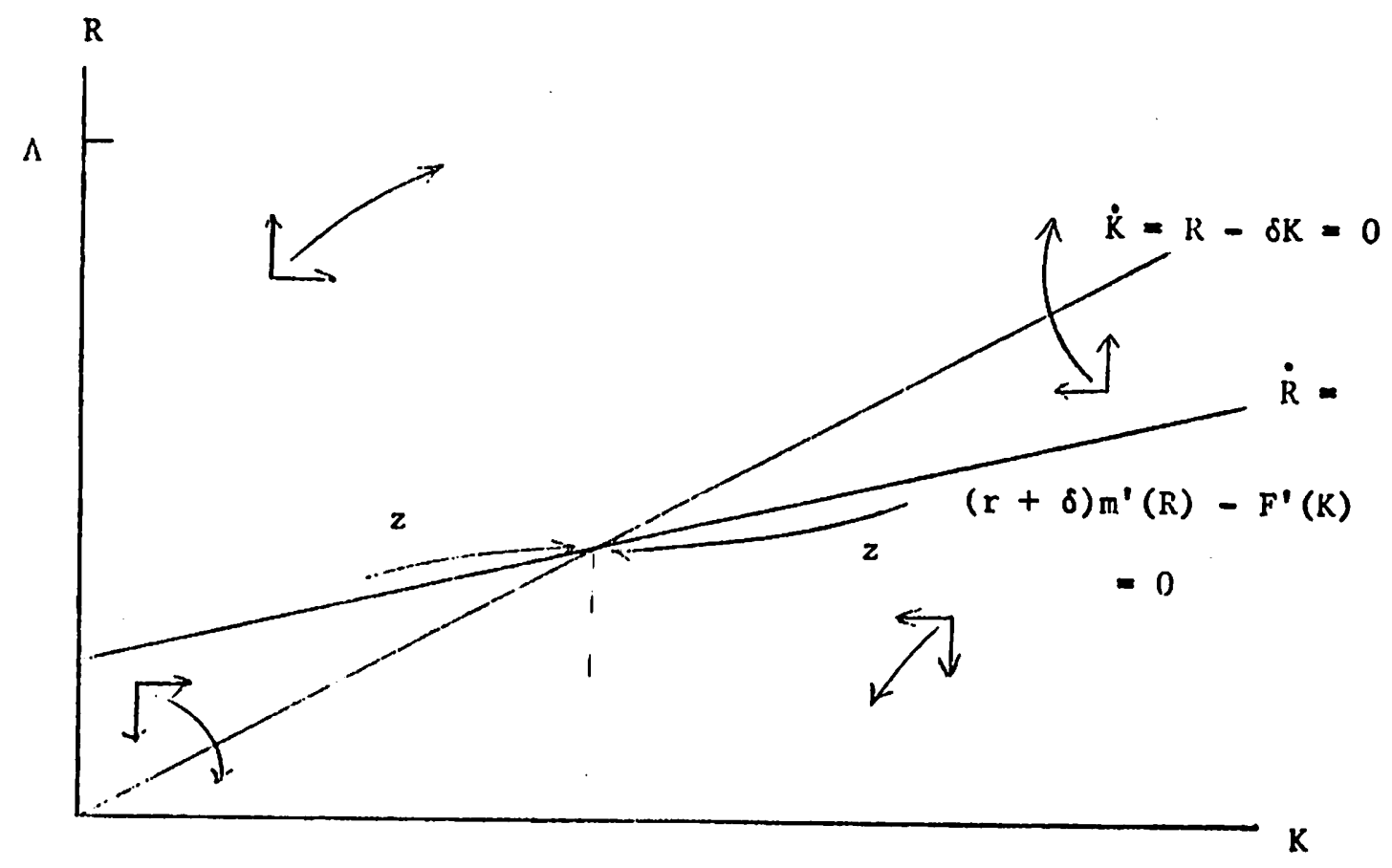

Figure 2-2: A phase diagram for the case $\mathrm{m}^{\prime \prime}(\mathrm{R})<0$

Here the path $z$ is an extreme path consistent with the steady state; however, it need not be a maximum path. Examination of second order conditions Is not a simple matter; however, some insight can be gained by characterizing the point at which the two lines $\dot{R}=0$ and $\dot{K}=0$ cross. Two possibilities are shown in Figure 2-3: 


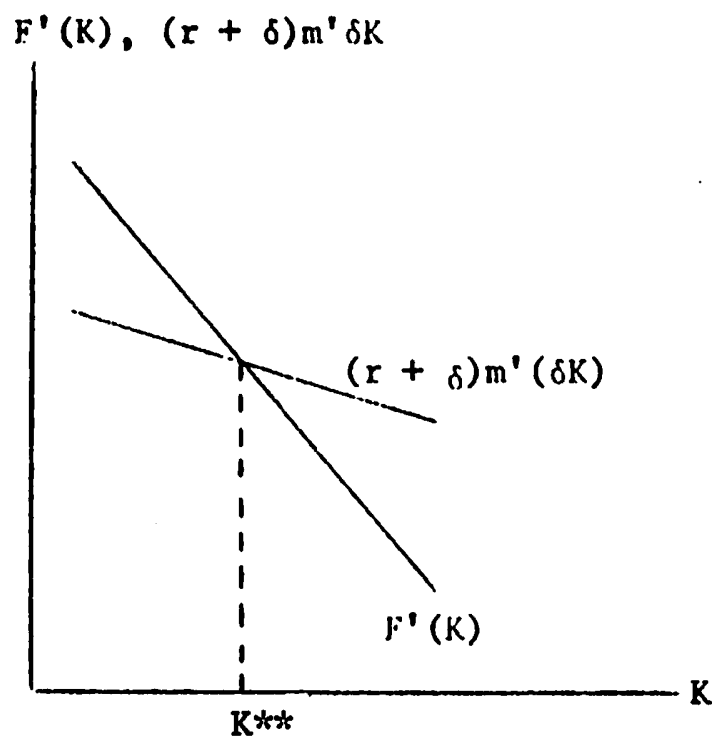

(a)

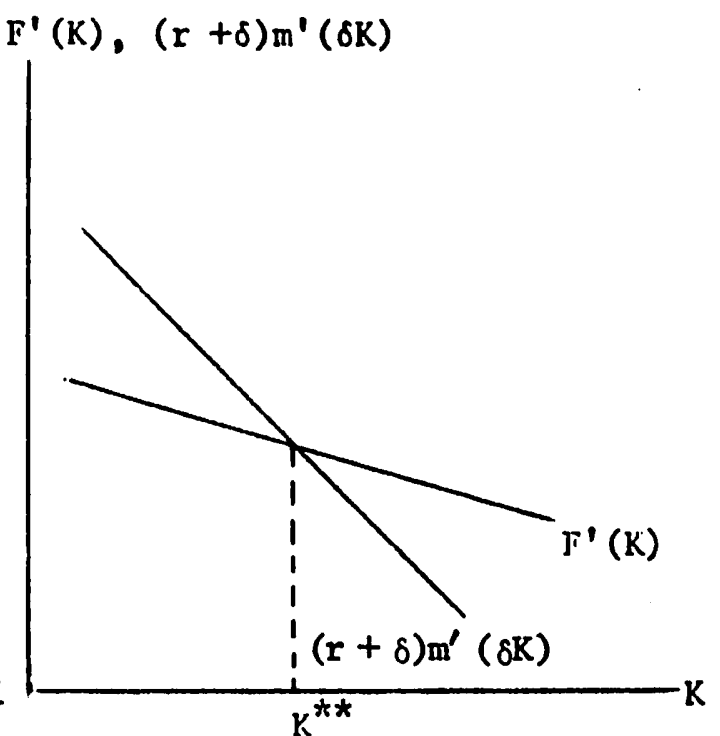

(b)

Figure 2-3: Marginal costs and marginal revenue products when $\dot{R}=0$

In Figure 2-3a, $\mathrm{K} * *$ is a maximum. Movement slightly to the left would forgo units of capital for which marginal revenue exceeds marginal cost. Movement to the right would involve purchase of capital for which the marginal cost exceeds marginal revenue. (Equivalently, $F^{\prime \prime}(K)-\delta(r+\delta) m^{\prime \prime}(\delta K)<0$. ) In this case, the steady state is a maximum and a path converging on that point could be expected to be a maximizing path.

Figure 2-3b represents a case in which $K * *$ is a minimum. Displacement to the left avoids purchase of capital for which the marginal cost exceeds the marginal revenue product. Displacement to the right would involve purchase of capital for which the opposite is true. $\left(F^{\prime \prime}(K)-\delta(r+\delta) m^{\prime \prime}(\delta K)>0\right)$ Here, paths converging on $\mathrm{K} * *$ would not be maximum paths. Further, maxima should involve eventual movement away from $\mathrm{K} * *$.

Now, if the path $\dot{R}=0$ intercepts the path $\dot{K}=0$ from above, as in Figure 2-2, then $(r+\delta) \mathrm{m}^{\prime}(R)$ must decrease more rapidly than $F^{\prime}(K)$ as $R$ and $\mathrm{K}$ are increased along the path $\mathrm{R}=\delta \mathrm{K}$. To see this, notice that having the path $\dot{R}=0$ flatter than the path $\dot{K}=0$ implies that $R$ is increased proportionately 
less than $K$ in order to maintain equality of $F^{\prime}(K)$ and $(r+\delta) m^{\prime}(R)$. Since Figure 2-2 involves a path for $\dot{R}=0$ which is steeper than the path $\dot{K}=0$, then Figure 2-2 would reflect functions like those depicted in Figure 2-3b and therefore $\mathrm{K}^{* *}$ is a minimizing point, at least relative to other possible stable K.

It arises that the lines $\dot{R}=0, \dot{K}=0$ might not cross. This would be likely under the very reasonable assumptions that $F^{\prime}(\infty)=0$ but $\mathfrak{m}^{\prime}(\infty)>0$. Since $\mathrm{m}^{\prime}(\mathrm{R})$ and $\mathrm{F}(\mathrm{K})$ are now both decreasing functions it is possible that no positive $K^{* *}$ exists which satisfies the equation $F^{\prime}\left(K^{* *}\right)-(r+\delta) m^{\prime}\left(\delta K^{* *}\right)=0$. The phase diagram, constructed as before, is shown in Figure 2-4.

$$
\dot{k}=\left[(r+\delta) m^{\prime}(R)-F^{\prime}(K)\right] / m^{\prime \prime}(R)=0
$$

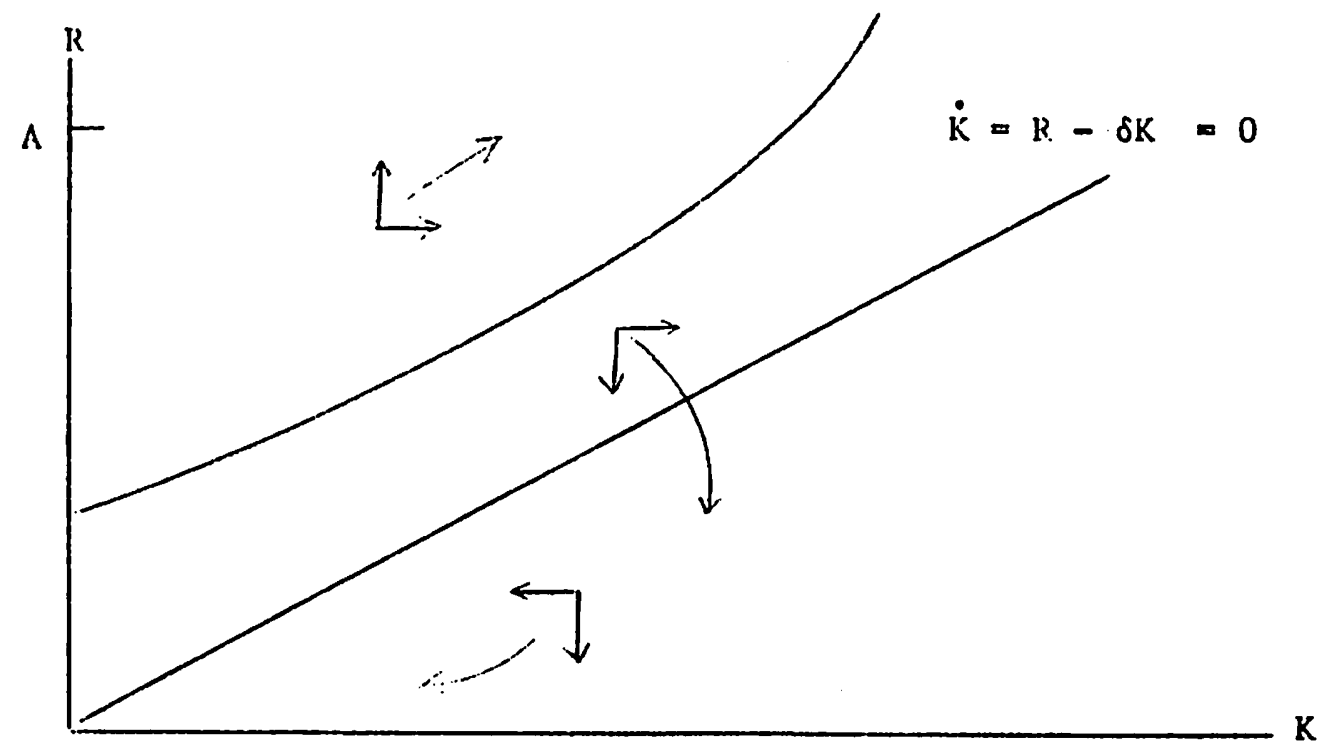

Figure 2-4: Phase diagram for the case $\mathrm{m}^{\prime \prime}(\mathrm{R})<0$, no $\mathrm{K} * *$

In this case, the feasible Euler paths will eventually have capital declining steadily toward zero. Ultimately the dwelling would be abandoned or demolished. Note that the landlord does maintain, and that his efforts do slow the rate of decline for capital. 
Two additional cases are introduced by the possibility that the line $\dot{R}=0$ may, under present assumptions, intercept the horizontal axis at positive $K$. One such case is shown in Figure 2-5.

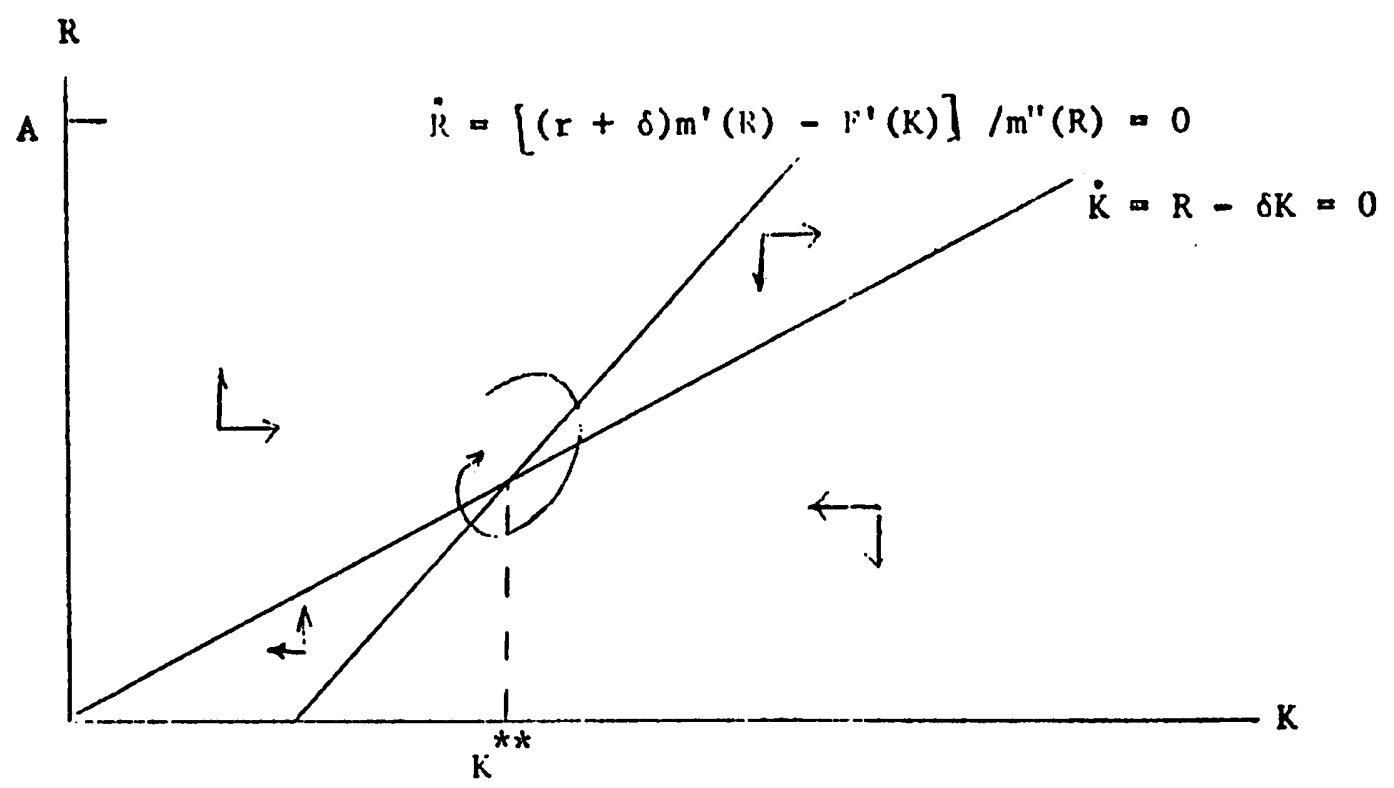

Figure 2-5: Phase diagram for the case $\mathrm{m}^{\prime \prime}(\mathrm{R})<0$

Again the Hamiltonian is not concave in $R$, which means that $K^{* *}$ is not necessarily a maximum. But the discussion raised in connection with Figure 2-3 would apply and $\mathrm{K} * *$ does appear to be at least a local maximum. It is not possible to establish whether the cycling shown is stable, although convergence is reasonable if $\mathrm{K} * *$ is a maximum. In the case where $\dot{R}=0, \dot{K}=0$ do not cross (not shown) there is no steady state consistent with convergence to a constant $K$.

A further possibility is that marginal maintenance cost declines initially but eventually increases. If the range of decline is sufficiently large, this would introduce another case distinct from the one depicted in Figure 2-1. 
21

Consider a $U$-shaped cost function which reaches its minimum at $\hat{\mathbf{R}}$. This gives two additional cases shown in Figures 2-6 and 2-7:

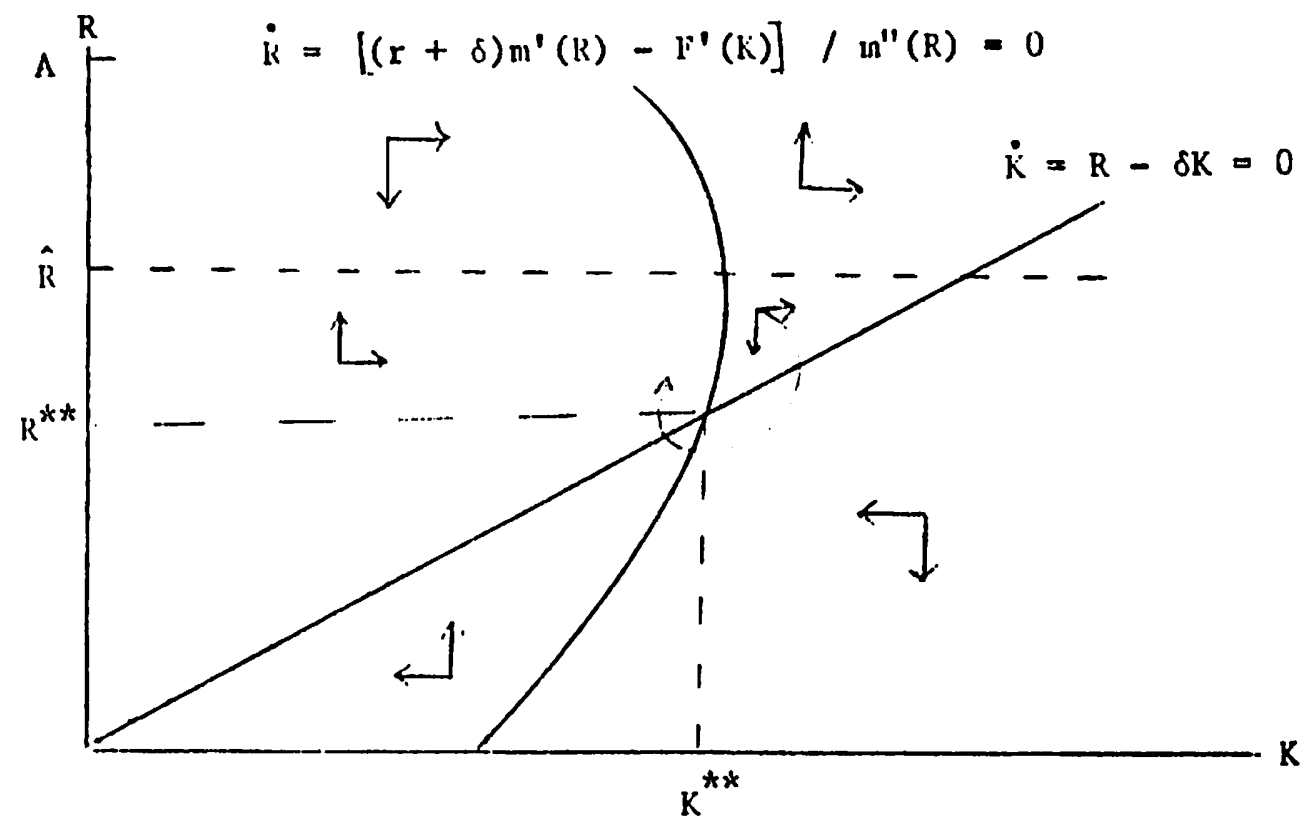

Figure 2-6: Phase diagram for the case $\hat{R}>R^{* *}$

In Figure 2-6, the minimum of $\mathrm{m}^{\prime}(\mathrm{R})$ occurs at $\hat{\mathrm{R}}>\mathrm{R} * *$. In this case $\mathrm{K} * *$ need not be a maximum, and the cycling need not converge toward $\mathrm{K} * *$. Figure 2-7 shows the alternative, that $\hat{R}<R^{* *}$. Here $\left(K^{* *}, R^{* *}\right)$ is a maximum, and presumably some or all of the paths leading to $\mathrm{K}^{\star *}$ are at least local maxima.

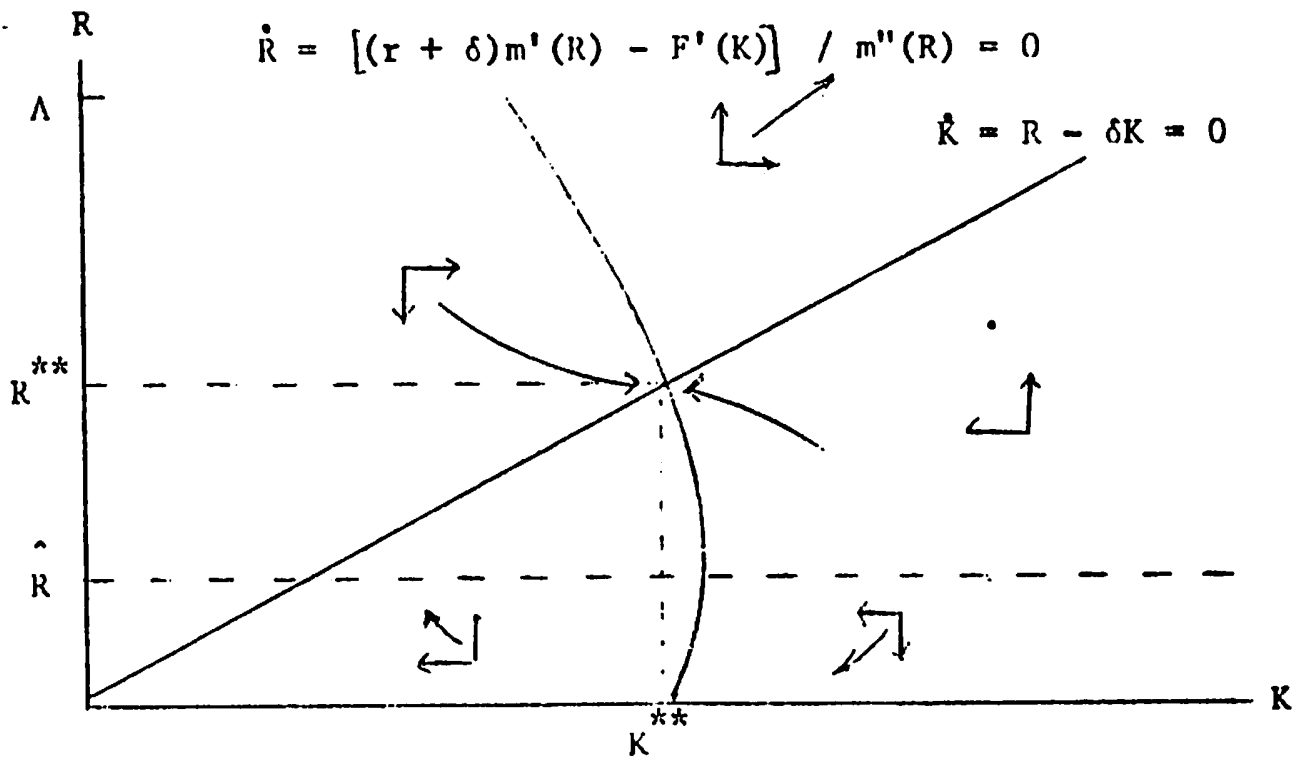

Figure 2-7: Phase diagram for the case $\hat{R}<R^{* *}$ 


\section{Increasing Rate of Decay}

A final possibility that has been suggested is that the underlying rate of decay may increase monotonically with time. With $\delta=\delta(t), \delta^{\prime}(t)>0$, filtering would occur even with a convex cost function. No simple diagrammatic representation is possible, but the result would approximate Figure 2-1 with $\mathrm{K} * *$ moving steadily to the left. While this case does have an intultive appeal, It has some shortcomings as an explanation for filtering. First, the empirical Impetus for an assumption of increasing decay is treacherous. Accumulated depreciation may be increasingly apparent with time, and that observation may suggest the assumption of increasing $\delta(t)$. But $\delta$ represents the underlying rate of depreciation, not an accumulation. While the need for repair may come up suddenly, the deterioration presumably was there all along. Even if there are "one hoss shays," which deliver unchanged service until they fail, those components of the house presumably can be replaced. The replacements might be expected to last as long as the originals. Second, for this approach to yleld filtering requires not just a moderate once over change in $\delta$, but a continuing increase with $\delta(t)$ becoming quite large. 
III. Empirical Implementation

The previous discussion shows that while conventional assumptions on the maintenance cost function imply that units do not depreciate indefinitely, several alternatives cannot be ruled out. These results prompt an empirical investigation that is reported on very briefly here. A detailed discussion of estimators, data, and functional forms is presented in [13]. The major departure of this work from previous efforts is the concentration here on the behavior of the flow of services rather than on structure value. The procedure chosen negates the problem of disentangling vintage and time effects and avoids the use of a structure price index which must be sensitive to interest rates and expectations. A further advantage of this approach is that service transactions occur regularly while capital transactions occur infrequently and at odd intervals. Previous studies have unnecessarily accepted the restriction, appropriate to most other capital goods, of viewing only the behavior of the stock price.

Ideally we would like to observe the relationship, in an undisturbed environment, between this year's quantity of housing service and last year's. Since disturbances will generally intrude, it is necessary to include changes in the exogenous variables as additional arguments in any estimated equation. This suggests the form

$$
Q_{t}=(1-\gamma) Q_{t-1}+\left(Z_{t}-z_{t-1}\right) \beta+u_{t}
$$

where $Q_{t}$ is the quantity of housing service provided by a dwelling at time $t, z_{t}$ is a vector of exogenous variables, $u_{t}$ is the stochastic term and $\gamma$ and $\beta$ are parameters to be estimated. (This is shown in [13] to be a transformation of the supply function under certain additional restrictions.) 
The primary data for this study are the Panel Study of Income Dynamics by the University of Michigan, Institute for Social Research. This study reports, among other things, a household's contract rent for the eight years covered by the study, 1968-1975. By selecting a subsample of renters who had not moved, it was possible to construct a number of short time series which were pooled to create an adequate sample. Further restrictions were Imposed to take account of rent control (New York), to eliminate obvious coding errors, and to limit the sample to the thirty-nine cities for which the B.L.S. reports household budget data [1]. The household observations on rent were transformed by dividing by a price measure. The price measures for each city are constructed by regarding 1968 housing as the numeraire and generating the "price" $P_{1 t}$ for later years from the B.L.S. budget studies. $P_{1 t}=R_{1 t} / R_{168}$ where $R_{1 t}$ is the B.L.S. reported low budget housing cost for city $i$ in year $t$. Such a measure can be literally correct (up to a multiplicative constant) only if the relationship between quantity and rent (expenditure) is linear at a given location and time. However, for the functional form chosen, the approximation should be close so long as the relationship between the "true" (unobservable) quantity and rent can be approximated over a narrow quantity and rent can be approximated over a narrow range by a linear function. Three additional variables, representing the exogenous factors in the model were appended to the rent data. These were: an indicator of the marginal price of housing, an indicator of maintenance and operating input prices, and an interest rate. The marginal price of housing is proxied by the ratio of middle standard housing cost to low standard housing cost in the B.L.S. family of four budgets [7, 26]. This variable, labelled AlFA 
was expected to have a positive sign. Operating and maintenance input prices are proxied by OPCO, the corresponding component of the consumer price index [7]. Finally the variable RATE is the yield on one year treasury bills. This short term rate was chosen because maintenance of a structure is, at the margin, a short term commitment. A landlord might maintain at one moment and "withdraw" funds the next by "undermaintenance". Thus the return on a one year commitment was regarded as the appropriate messure of opportunity cost.

Pooling time series and cross section data presents some special econometric problems. Observations from one time series may tend to be more like one other than they are like elements of other time series. This view of the structure of error terms has given rise to the error componente approach. Nerlove [16] provides a discussion of pooling in the case of a lagged dependent variable. In the case in which time invariant effects may be assumed absent, a generalized least squares estimate requires only the determination of a parameter $\rho$ which Nerlove calls the "Intra class correlation coefficient". The parameter is equal to the ratio of the between group variance of errors to the total variance of errors. In this case $\rho$ is estimated by a search procedure as discussed in Dhrymes [2]. Results are shown in Table 1.

The equation has high explanatory power which is not surprising given the presence of a lagged dependent variable. All coefficients have the expected sign, although only the lagged dependent variable 18 significant at $5 \%$. The key result here is the coefficient on the lagged dependent variable. The depreciation rate implied by the coefficient of QIAG is .36 percent. This is not significantly different from zero, but is significantly different from 
the $2 \%$ value which appears to be invoked frequently in the housing literature. These results would call to question the ad hoc assumptions which give rise to filtering models and suggest that aging may not be an overwhelming force In shaping cities.

Table 1 Regression Results

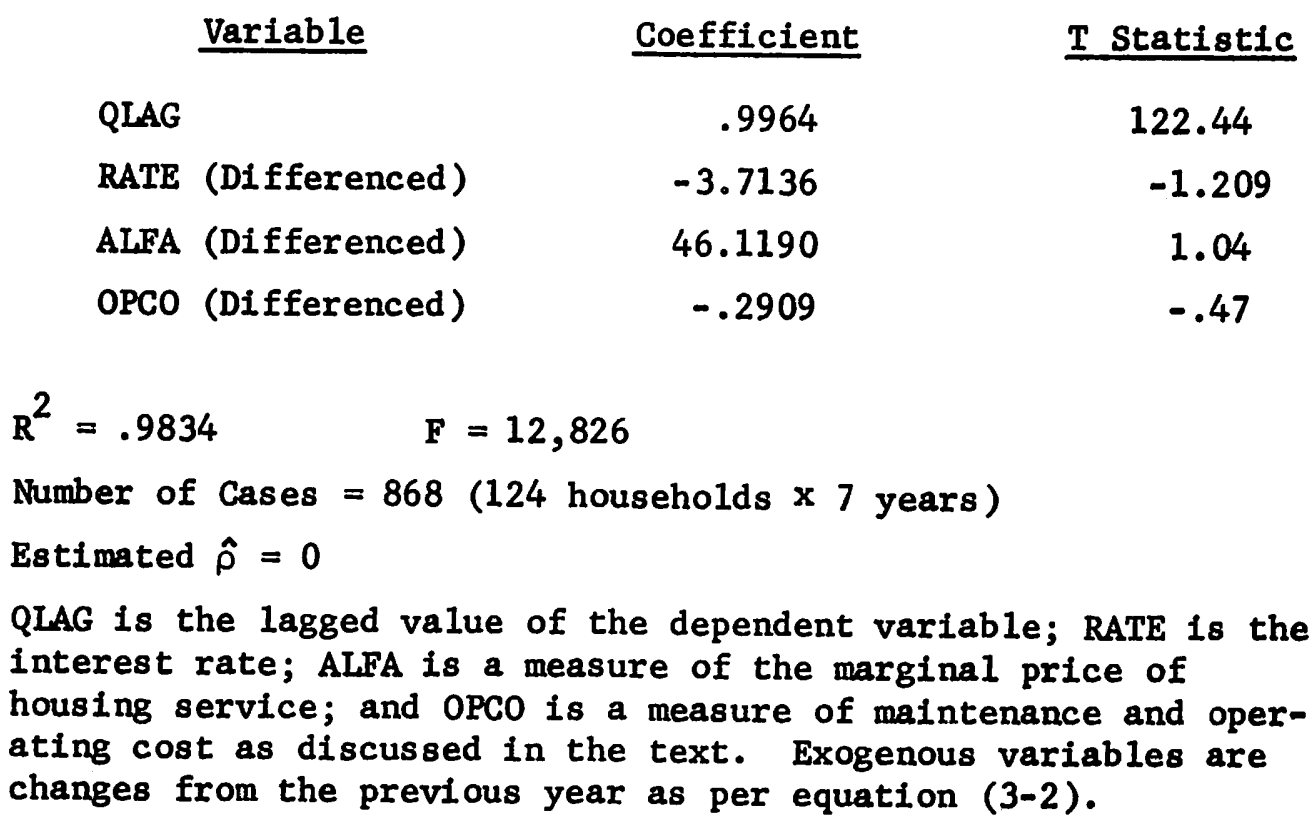

Conclusions

The major result of this study is that the view that dwellings deteriorate with time is not supported by abstract theory or by empirical results. While filtering is a very logical response to disequilibrium, its relevance for a stationary equilibrium is questionable. The empirical test is admittedly a first generation effort, so it would be premature to claim the filtering models are refuted. Nonetheless, the results reported here must be regarded as evidence against the prevailing view. 


\section{BIBLIOGRAPHY}

1. Frank DeLeeuw, and Raymond J. Struyk. The Web of Urban Housing. Washington, D.C. 1975.

2. Phoebus J. Dhrymes. "On the Treatment of Certain Recurrent Nonlinearities in Regression Analysis," Southern Economic Journa1, 33 (1966), 187-193.

3. Leo Grebler, David M. Blank, and Louis Winnick. Capltal Formation in Residential Real Estate. Princeton, 1956.

4. William G. Grigsby. Housing Markets and Public Policy. Philadelphia, 1963.

5. Robert E. Ha11. "Technical Change and Capital from the Point of View of the Dua1," Review of Economic Studies, 35 (1968), 35-46.

6. "The Measurement of Quality Change from Vintage Price Data," in Price Indexes and Quality Change, ed. Zvi Griliches. Cambridge, Mass., 1971, 240-271.

7. Handbook of Labor Statistics, Bulletin numbers 75-190, 76-769. Washington, D.C., 1976. (A report of the U.S. Department of Labor, Bureau of Labor Statistics.)

8. Gregory Ingram, and Yitzak Oran. "The Behavior of Housing Producers," an unpublished paper delivered at the National Bureau of Economic Research, Conference on Research on Income and Wealth, May 15-16, 1975.

9. John F. Kain, J. Royce Ginn. The Detroit Prototype of the N.B.E.R. Urban Simulation Model. New York, 1972.

10. John Kain, and J. M. Quigley. "Measuring the Value of Housing Quality," Journal of the American Statistical Association (June, 1970), 532-537.

11. Ira S. Lowry. "Filtering and Housing Standards, A Conceptual Analysis," Land Economics, 35 (November, 1960), 362-370.

12. Monthly Labor Review, 99-8. Washington, D.C., 1976. (A publication of the U.S. Department of Labor, Bureau of Labor Statistics.)

13. Margolis, Stephen. "Depreciation of Capital in Housing." PhD. Dissertation. U.C.L.A. (1978).

14. Richard F. Muth. Cities and Housing. Chicago, 1969.

15. "A Vintage Model of the Housing Stock," Papers of the Regiona1 Science Association, 30, (1973), 141-155. 
16. Marc Nerlove. "Experimental Evidence on the Estimation of Dynamic Economic Relations from a Time Series of Cross Sections," Econometrica, 39, 2 (March, 1971), 359-382.

17. A Panel Study of Income Dynamics, 1968-1975 Interviewing Years. Ann Arbor, 1975. (A computer tape compiled by Survey Research Center, University of Michigan Institute for Social Research.)

18. Richard U. Ratcliff. Urban Land Economics. New York, 1949.

19. Sherwin Rosen. "Hedonic Prices and Implicit Markets: Product Differentiation in Pure Competition," Journal of Political Economy, 82, 1 (February, 1974), 34-55.

20. Jerome Rothenberg. Economic Evaluation of Urban Renewa1. Washington, D.C., The Brookings Institution, 1967.

21. Wallace F. Smith. "Filtering and Neighborhood Change," Research Report No. 24, Center for Real Estate and Urban Economics of the Institute of Urban and Regional Development. Berkeley, California 1964.

22. Mahlon R. Straszheim. "Estimation of Demand for Urban Housing Services from Household Interview Data," Review of Economics and Statistics, 55, 1 (February, 1973), 1-3.

23. James L. Sweeney. "Quality, Commodity Hierarchies and Housing Markets," Econometrica, 42, 1 (January, 1974), 147-167.

24. "A Commodity Hierarch Model of the Rental Housing Market," Journal of Urban Economics, 1 (1974), 288-323.

25. Akira Takayama. Mathematical Economics, Hinsdale, Il1ino1s, 1974.

26. Three Budgets for an Urban Family of Four Persons, 1969-1970, Supplement to Bulletin 1570-5. Washington, D.C. (A report of the U.S. Department of Labor, Bureau of Labor Statistics.)

27. Underwriting Manual. Washington, D.C., 1952. (A publication of the U.S. Federal Housing Administration.) 